\title{
ALGUMAS MEMÓRIAS SEGUNDO ANTONIO CANDIDO
}

\section{SOME MEMORIES BY ANTONIO CANDIDO}

\author{
Afonso Henrique Fávero ${ }^{1}$ \\ Universidade Federal de Sergipe
}

\section{RESUMO}

Acompanhamento de posições de Antonio Candido quanto a certas obras de cunho pessoal no âmbito da literatura brasileira. Procura-se trazer a primeiro plano a visada crítica aguda e certeira do estudioso. $\mathrm{O}$ artigo contempla também em seu início uma visão do desenvolvimento da literatura de memórias no Brasil.

PALAVRAS-CHAVE: Antonio Candido; Memorialismo brasileiro; Formação.

\begin{abstract}
Accompaniment of positions of Antonio Candido regarding certain personal works within the Brazilian literature. It seeks to bring to the forefront the acute and accurate critical view of the scholar. The article also contemplates in its beginning a vision of the development of the literature of memories in Brazil.
\end{abstract}

KEYWORDS: Antonio Candido; Brazilian memorialism; Formation.

\section{INTRODUÇÃO}

Já faz algum tempo que o interesse pela literatura de memórias entre nós tem crescido a olhos vistos, e isso se deve, ao que parece, ao acentuado desenvolvimento do gênero, que encontrou, particularmente nas últimas décadas, inúmeros cultivadores em nossas letras. Trata-se de uma produção variada, desnivelada, com propósitos ora voltados para o dado essencialmente histórico, ora almejando atingir planos mais elevados da elaboração artística; ou ainda, com frequência, buscando conciliar essas duas esferas, que afinal nada possuem de antagônico.

Uma produção literária de tal natureza vem demonstrando vigor incomum ao menos desde os anos 30 do século passado para cá, se comparada à produção anterior a tal período. Mas, a bem da verdade, qualquer desenvolvimento desse gênero literário aqui no Brasil acabaria mesmo por chamar a atenção em face da pequena representatividade que obteve no século XIX e nas primeiras décadas do século XX.

Como é manifesto, a produção dominante de nossa literatura no período de sua formação esteve (e, de certo modo, ainda talvez continue) voltada sobretudo para a poesia e a prosa de ficção. É visível, porém, a presença mais intensa e mais articulada de textos de memórias, formando, por conseguinte, um conjunto mais coeso, bastante diferente daquele quadro de produções isoladas, embora de valor, de um Francisco de Paula Ferreira de Rezende, de uma Helena Morley, de um Joaquim Nabuco.

Convém relembrar um pouco o percurso da literatura brasileira e verificar que no século XIX o romance, por suas próprias características de gênero aberto, encarregava-se de descrever a nossa realidade, fazendo-o a partir do seu inerente acento artístico e também em função do "projeto nacionalista" que norteava o nosso Romantismo, o que terminou por conferir-lhe uma

\footnotetext{
${ }^{1}$ Doutor em Literatura Brasileira pela Universidade de São Paulo e professor de Literatura Brasileira na Universidade Federal de Sergipe. E-mail: ahfavero@ig.com.br
} 
"verdadeira forma de pesquisa e descoberta do país", conforme os termos de Antonio Candido em seu ensaio esclarecedor (CANDIDO, 1975, vol. II, p. 109-118). O que havia era um esforço dos nossos romancistas em dar conta das formas de vida em um país, de um lado, de tão larga geografia, e, de outro, tão aparentemente rarefeito ainda quanto às relações sociais nele estabelecidas. Tarefa abraçada como missão, a ficção romântica brasileira a cumprirá quase que programaticamente, abordando tanto quanto possível as esferas da incipiente, ainda que diversificada, cena do país - vida na cidade, vida rural e vida primitiva. E dessa forma, tal esforço desejava resultar em "tomada de consciência da realidade brasileira" (CANDIDO, 1975, vol. II, p. 114), objetivo cujo alcance atribuiria à nossa literatura a capacidade de, como realização artística, revelar também nossa configuração histórica e social.

Por sinal, a aptidão que a literatura possuía em retratar nossa evolução histórica e de definir as marcas distintivas da pátria convertia-se em critério de avaliação para a crítica brasileira da segunda metade do século XIX e início do século XX, conforme nos indicam as observações de João Alexandre Barbosa:

\begin{abstract}
Ora, se nos ativermos a alguns dos principais textos críticos que constituem a nossa tradição entre a segunda metade do século XIX e inícios do século XX, não será difícil verificar de que modo todos eles estão configurados sob uma perspectiva que eu chamaria de paixão interpretativa. Era natural: desde o começo das reflexões críticas no Brasil, mesmo as menos sistemáticas, empreendidas pelos próprios criadores entre os séculos XVII e XIX, o debate centra-se na busca de uma diferença com relação à Europa e, portanto, pela identidade nacional. Neste sentido, a interpretação da literatura era subsidiária da preocupação maior em identificar os traços culturais que serviam de base para uma definição abrangente do país. (BARBOSA in MEYER, 1986, p. XV).
\end{abstract}

Lembre-se também que, como sistema minimamente organizado, a literatura no Brasil ainda pode ser considerada relativamente jovem. O período de sua configuração remonta à metade do século XVIII, prolongando-se até a segunda metade do século XIX, conforme o conhecido ponto de vista adotado por Antonio Candido em seu já mencionado Formação da literatura brasileira.

A literatura de memórias entre nós, por sua vez, mostra-se mais recente ainda, visto que somente da segunda metade do século XIX em diante, e sobretudo ao seu final, é que tal literatura conhece um pouco de relevo, embora seja indisfarçável o caráter de baixa densidade que apresenta no quadro geral da nossa produção literária. Muitas obras redigidas nessa época somente virão à luz no século seguinte devido ora ao insólito da publicação de obras de tal natureza, ora ao desejo explícito do autor, que determinava para muitos anos depois uma eventual divulgação de sua trajetória de vida, como é o caso, por exemplo, das memórias do Visconde de Taunay. ${ }^{2}$ Nelson Werneck Sodré assim nos descreve a situação:

Só na segunda metade do século XIX, pois, - a época em que o Romantismo domina as
letras e o teatro - aparecem livros de memórias, na maior parte livros de assentos,
simples registros de fatos ligados diretamente a quem escreve, que o impressionam e
exigem a escrita, e a correspondência começa a ter função um pouco além do seu
caráter utilitário e imediato. É raro, entretanto, no início da segunda metade do século,
a consagração do livro para memórias, assentos ou correspondência. Mesmo quando
desse tempo, os exemplos isolados mostram que foram reduzidos a livro muito depois,
aproveitando originais e manuscritos que os cuidados familiares resguardaram da
destruição. Para os fins do século XIX, entretanto, quando se anunciam as

2 "Estas Memórias só podem, só devem ser entregues à publicidade depois de 22 de fevereiro de 1943, isto é completos cem anos da época do meu nascimento, ou cinquenta anos de 1893, data em que as hei de depor em lugar seguro (a) Visconde de Taunay. Petrópolis, 26 de junho de 1892." A declaração do autor foi aposta aos originais de suas memórias, conforme texto introdutório às mesmas assinado por seus filhos Affonso de E. Taunay e Raul de Taunay em 24 de dezembro de 1946. 
transformações que vão movimentar o quadro brasileiro, chegando à mudança de regime, aparecem os primeiros livros de memórias. (SODRÉ, 1976, p. 345).

Outro bom exemplo do que refere Nelson Werneck Sodré figura no livro organizado por Gilberto Freyre baseado em anotações de Félix Cavalcanti de Albuquerque Melo, patriarca de uma família pernambucana, nascido em 1821 e morto em 1901. Em prefácio à primeira edição de Memórias de um Cavalcanti, Diogo de Melo Meneses, bisneto do autor, indica as circunstâncias de publicação da obra e a motivação para tanto: "Gilberto Freyre destaca o interesse das memórias de Félix Cavalcanti para os estudiosos da História Social no Brasil do século passado. Este é o motivo principal para a sua publicação no livro dedicado por ele à reconstituição da figura do velho patriarca" (MENESES in FREYRE, 1989, p. CXXXIV).

Naturalmente a ficção sempre procurou estar atenta às transformações ocorridas no "quadro brasileiro" e assim continuar cumprindo sua tarefa de traçar o perfil do país. A presença gradativa dos textos de memórias demonstrou que, para uma tarefa dessa dimensão, a nossa literatura começava a voltar-se rumo a um gênero que apresentava potencial considerável de contribuição nesse campo. Parece, pois, procedente dizer que as memórias pessoais, na medida em que refletiam o meio em que se situava o autor, constituíam uma espécie de força auxiliar da ficção no intuito de mapear a realidade brasileira, mesmo que isto não representasse um projeto específico de atuação.

Nunca deixou de existir, com efeito, aquela vocação de "aplicação social e responsabilidade na construção de uma cultura" (CANDIDO, 1975, vol. II, p. 115) por parte do romance brasileiro, bastando para comprová-la a lembrança de apenas alguns nomes mais recentes como Lima Barreto, Graciliano Ramos, José Lins do Rego, Jorge Amado, Dyonélio Machado, Érico Veríssimo, Guimarães Rosa, Antônio Callado.

Ora, essa manifestação mais acentuada da literatura de memórias coincide, e possivelmente não por acaso, com um momento importante do nosso romance, do qual é numa boa medida tributária; inclusive porque, como é natural, muitos autores têm um pé em cada um desses gêneros segundo os casos de Oswald de Andrade, Graciliano Ramos, Érico Veríssimo e Cyro dos Anjos, para ficarmos somente em alguns exemplos notórios. E assim, no que diz respeito ao enfoque das questões nacionais, os textos de memórias acabam por desempenhar papel análogo ao do romance, com a diferença de que aqueles não necessitam, em princípio, apresentar a fatura estética própria deste último. Ocorre, entretanto, que muitas vezes apresentam. Ganham vulto artístico, ombreiam-se com os melhores romances, utilizam-se de suas técnicas, chegam a confundir-se com eles; e, além disso, mantêm importância suplementar pela condição de testemunhos da realidade, que efetivamente são, devido ao manifesto parentesco com o discurso histórico. Não é por outra razão que vários volumes de memórias pertencem a coleções temáticas como a "Documentos Brasileiros", da editora José Olympio, ou "Retratos do Brasil", da Civilização Brasileira.

Do ponto de vista literário, a validade dessas obras está, pois, diretamente ligada à capacidade de operar aquela síntese entre os dados fornecidos pela realidade e os meios expressivos de que o autor é dotado. Significa dizer que esta operação consiste justamente em expandir os aspectos contingentes da matéria tratada - no caso o relato da vida pessoal - a níveis mais abrangentes, mais universais, imprimindo-lhe por tal meio caráter mais exemplar.

\section{De Antonio Candido, o estímulo}

Lemos uma pequena e notável passagem situada logo no princípio das memórias de Oswald de Andrade, iniciadas em 1952 e publicadas em 1954. Ei-la: "Antonio Candido diz que uma literatura só adquire maioridade com memórias, cartas e documentos pessoais e me fez jurar que tentarei escrever já este diário confessional" (ANDRADE, 1974, p. 6). 
Ressalte-se que essa instância de Antonio Candido a Oswald de Andrade ocorreu justamente à época em que finalizava a redação da sua Formação da literatura brasileira. É de se imaginar, por conseguinte, que o autor andaria muito envolvido com assuntos dessa natureza, ou seja, assuntos concentrados em problemas de formação, amadurecimento, consolidação e maioridade de nossa literatura.

Também é preciso lembrar que tal pedido se dá no começo dos anos 50, o que significa dizer que a literatura brasileira, naquele período ainda carente de textos ligados ao gênero memorialístico, já daria alguns sinais de crescimento nesse campo. Com a agudeza habitual, Antonio Candido certamente percebia o potencial considerável que isto representava para um desenvolvimento literário mais amplo, e daí o estímulo veemente a Oswald de Andrade (e quem sabe a quantos mais!), o belo prefácio que escreveu para suas memórias, os penetrantes estudos dedicados à literatura pessoal entre nós.

Duas décadas depois, o crítico nos oferece uma explicação consistente para o crescimento desse tipo de produção ao tratar da situação de nossa literatura lá pelos inícios dos anos 70 . Antonio Candido faz um balanço do panorama literário nacional daquela época, enfatizando que as tendências de vanguarda distanciavam-se da orientação que predominara até então "na própria concepção de literatura, pois não estão mais interessadas na transposição do mundo, e sim em criar pequenos mundos autônomos, que podem lembrar mais ou menos a realidade do mundo que conhecemos, mas não tiram disto o seu significado principal" (CANDIDO, 1977, p. 11). Um dos efeitos dessa exacerbação das vanguardas estaria no emprego não-referencial da palavra e na desarticulação da ordem sintática do discurso, especialmente na poesia, mas com reflexos que entram também pela prosa de ficção.

A partir de constatações dessa natureza, o autor prossegue com suas considerações sobre o assunto e apresenta ilações, como a que segue:

[...] na medida em que é empurrada para fora da poesia e mesmo do romance, esta vocação referencial volta sob outras formas, para satisfazer a uma necessidade profunda da nossa sensibilidade e da nossa inteligência.

Talvez seja este um dos motivos responsáveis por um traço característico da literatura brasileira atual: a importância crescente dos livros de autobiografia, gênero que sempre foi raro no Brasil, apesar de algumas exceções famosas. (CANDIDO, 1977, p. 12).

Certamente a perspectiva possível sobre a nossa literatura de memórias naquela época tinha de ser essa mesma, isto é, uma produção exígua com um ou outro momento de maior elevação. Ainda não havia um distanciamento favorável a possibilitar a consideração, por exemplo, do real avanço que os anos 60 trouxeram com as obras de nomes importantes como Afonso Arinos de Melo Franco, Cyro dos Anjos, Carlos Drummond de Andrade, Murilo Mendes, Brito Broca, entre outros. Assim, aquelas manifestações mais antigas de um Nabuco, de um Augusto Meyer ou de um Graciliano Ramos acabavam por sobressair mais como fenômenos isolados do que como parcelas integrantes de um conjunto em sua fase de constituição.

Mas alguma coisa já se fazia sentir de maneira clara, que é precisamente aquela "importância crescente dos livros de autobiografia" entre nós. Atualmente tornou-se possível perceber com mais facilidade que as produções dentro do gênero compõem uma teia de relações e mostram a existência de uma linha evolutiva no processo. É certo que o crescimento desse tipo de literatura deve estar associado à ocupação de um vazio deixado pela ficção brasileira, como apontou Antonio Candido. De qualquer modo, talvez não seja menos certo julgar que tal crescimento tem ocorrido porque justamente veio a encontrar uma pequena tradição nas nossas letras, suficiente todavia em fornecer-lhe o rumo necessário para prosseguir em seu desenvolvimento.

Isto posto, os passos seguintes deste trabalho dedicam-se a acompanhar uma ou outra posição de Antonio Candido a respeito de determinados livros de memórias no Brasil, conforme 
sugere seu título, buscando salientar a perspicácia e a sensibilidade do crítico na compreensão do que representaram tais obras para o fortalecimento da literatura brasileira. Como se trata de um apanhado geral com matéria condensada, a exposição dos pontos de vista do autor vai surgindo numa sequência justaposta e contínua, sendo delimitados por subtítulos compostos pelo nome dos memorialistas envolvidos, apenas com o propósito de facilitar a visualização dos limites entre um autor e outro. O fato de figurarem num só bloco os nomes de Carlos Drummond de Andrade, Murilo Mendes e Pedro Nava, como veremos abaixo, deve-se à circunstância de Antonio Candido tê-los estudado em conjunto num ensaio a respeito da presença de poesia e ficção nas memórias de autores mineiros.

\section{Lima Barreto}

Antonio Candido aponta o ano de 1933 como um marco importante para o memorialismo brasileiro devido ao sucesso das Memórias, "sinceras e medíocres", de Humberto de Campos. Posteriormente é que o gênero assumiria caráter mais literário, "desprendendo-se lentamente do documentário para se tornar uma construção de estilo, como ocorre com Infância, de Graciliano Ramos, de 1945, e na primeira parte de Um homem sem profissão, de Oswald de Andrade, de 1954" (CANDIDO, 1977, p. 12).

Mas antes de prosseguir, abra-se um parêntese para algumas observações sobre um autor cuja obra foi produzida entre o início do século XX e a Semana de Arte Moderna, cronologicamente anterior, portanto, ao marco referido de 1933. Trata-se do escritor carioca Lima Barreto, que não deixou memórias formalmente assumidas como tais, mas delas se aproximou de uma maneira, por assim dizer, oblíqua, se levarmos em conta seus escritos de natureza pessoal. É o caso particularmente das obras Diário intimo, Diário do bospício e O cemitério dos vivos. Este último, "memórias e reflexões em torno da vida num manicômio que o autor observou in loco, quando internado, por duas vezes, por motivos de alcoolismo, no Hospício Nacional" (BOSI, s.d., p. 101-102).

O cemitério dos vivos é um romance inacabado, amplamente concebido a partir das notas do Diário do hospício, que, por sua vez, também apresenta traços de elaboração romanesca. Em trabalho sobre tais escritos do autor, diz Antonio Candido: “[...] o Diário do hospício não pode ser considerado documento pessoal puro, porque a cada momento parece que o escritor está ficcionalizando a si mesmo e ao ambiente onde se encontra [...]" (CANDIDO, 1987, p. 47). Os dois textos foram publicados postumamente em um só volume e podem ser lidos em correlação estreita. Chama a nossa atenção a lucidez do autor (pois seus delírios eram episódicos e provocados pelo álcool) na percepção aguda daquele universo. Ele considerava apenas fatalidade a sua condição de interno no hospício - uma simplificação do problema, certamente -, mas mostrava-se capaz de reflexões muito sensatas sobre os loucos, os médicos, os funcionários, o sistema todo, enfim. Por este ângulo, o texto apresenta um certo parentesco com Memórias do cárcere, de Graciliano Ramos.

Sobre o Diário intimo, Antonio Candido afirma "que pode dar a impressão errada de ser pouco importante, ou de ser importante apenas como documento. [...] Tendo muita densidade de experiência e de escrita, eles servem para mostrar até que ponto na sua obra o autobiográfico pode funcionar como inventado" (CANDIDO, 1987, p. 42). Este estudo do crítico procura evidenciar na obra de Lima Barreto uma característica essencial: a de fundir, num movimento quase espontâneo, o depoimento direto de problemas pessoais e humanos com a capacidade de expressão artística, isto é, uma aliança entre vida e literatura, divisão, aliás, que para o autor de $O$ cemitério dos vivos não fazia muito sentido.

Chegamos então ao ponto que vale a pena ressaltar: a confluência do dado real e do ficcional, conforme vimos nas observações acima. Ora, os melhores exemplos da memorialística brasileira estão largamente imbuídos dessa confluência. Daí, portanto, o mérito de Lima Barreto, 
que já antecipava nos seus escritos pessoais uma característica tão marcante dos nossos bons memorialistas.

\section{Graciliano Ramos}

Infância, de Graciliano Ramos, desponta nos anos 40 sob o signo de uma continuidade literária, pois, embora um livro autobiográfico, revela-se bastante assemelhado à obra ficcional pregressa do autor, com um modo de ser bem característico de seus romances. Esse aspecto não escaparia, evidentemente, à observação de Antonio Candido registrada em "Ficção e confissão", estudo que se tornaria o maior referencial para a leitura de Graciliano:

Talvez seja errado dizer que Vidas secas é o último livro de ficção de Graciliano Ramos. Infância pode ser lido como tal, pois a sua fatura convém tanto à exposição da verdade quanto da vida imaginária; nele as pessoas parecem personagens e o escritor se aproxima delas por meio da interpretação literária, situando-as como criações. (CANDIDO, 1992, p. 49).

De um modo geral, os memorialistas saem-se melhor quanto mais se distancia no tempo a matéria recordada. Com efeito, as imagens da vida infantil costumam resultar em páginas mais expressivas, e isto provavelmente porque exigem trabalho de evocação mais acentuado. Ou seja, o autor se vê na contingência de exumar um passado longínquo, que só se rende com a colaboração decisiva de apelos à imaginação. A rememoração do período vivido torna-se possível com o complemento do vinco criador, sua configuração assume aspectos ficcionais, o efeito literário alcança altitude maior. Quando, porém, os fatos passados vão se aproximando do tempo da recordação, o que se nota por parte do memorialista é um anseio de fidelidade, uma vigilância mais ostensiva quanto à exatidão das lembranças, uma atitude, portanto, mais documental. Evidente que isto não significa um determinismo segundo o qual todo relato de imagens antigas contenha qualidade invariavelmente superior às imagens mais recentes. Não sendo determinismo, pode-se falar, no entanto, em tendência, sem grande risco de engano. Nomes importantes do nosso memorialismo encontram-se nessas condições, como Pedro Nava, Augusto Frederico Schmidt, Afonso Arinos de Melo Franco, Érico Veríssimo, Cyro dos Anjos.

Para o caso de Graciliano Ramos podemos recorrer uma vez mais ao estudo de Antonio Candido, "Ficção e confissão". Ali o pressuposto fundamental é que as memórias do autor formam um conjunto orgânico em relação à sua obra ficcional:

\footnotetext{
Depreende-se, pois, que as reminiscências não se justapõem à sua obra, nem constituem atividade complementar, como se dá na maior parte dos casos. Pertencemlhe, fazem parte integrante dela, formando com os romances um só bloco, pois são essenciais para a compreensão da mesma ordem de sentimentos e ideias, dos mesmos processos literários que observamos neles. (CANDIDO, 1992, p. 66).
}

Assim, Infância e Memórias do cárcere surgem como um passo de continuidade espontânea, orientados para o propósito de se oferecer uma visão mais integral do homem e do mundo, conforme sugere o projeto literário do escritor. "A autobiografia foi um caminho que escolheu e para o qual passou naturalmente, quando a ficção já não lhe bastava para exprimir-se" (CANDIDO, 1992, p. 66).

O próprio Antonio Candido faria mais tarde uma revisão desse ponto de vista, mantendo o argumento central - "Mas ainda me parece justo o pressuposto básico, isto é, que ele passou da ficção para a autobiografia como desdobramento coerente e necessário da sua obra" (CANDIDO, 1992, p. 11) -, relativizando, entretanto, o peso literário de Memórias do cárcere, antes tomado em pé de igualdade com a produção anterior de Graciliano: 
O que não parece mais defensável é que as duas fases tenham o mesmo nível literário, como o ensaio deixa implícito. Se Infância o mantém, o mesmo não acontece com o livro puramente autobiográfico, Memórias do Cárcere, apesar da sua força e do valor como documento humano. (CANDIDO, 1992, p.11).

\title{
Oswald de Andrade
}

Projetadas para vários volumes, mas limitadas pelas circunstâncias apenas ao inicial, as memórias de Oswald de Andrade figuram entre aquelas fundamentais da literatura brasileira. Trata-se de um bom exemplo de que a obra centrada no passado não necessita firmar-se em aspectos puramente documentais. Em Um homem sem profissão avulta antes um complexo de impressões, bastante eficaz em nos revelar a realidade humana do autor e o universo no qual se move. Ao optar por trazer dessa forma a primeiro plano os conteúdos da subjetividade, ou, dizendo de outro modo, deixando que a experiência passada apareça impregnada das sensações mais particulares, quer estejam estas dentro de um ritmo mais organizado, quer apareçam em notações meio dissipadas, o resultado é que o texto eleva-se em substância ficcional e artística. Como de hábito, vamos encontrar uma bem dirigida síntese sobre tal processo no prefácio de Antonio Candido à obra de Oswald de Andrade:

\begin{abstract}
Um escritor que fez da vida romance e poesia, e fez do romance e da poesia um apêndice da vida, publica as suas memórias. Vida ou romance? Ambos, certamente, pois em Oswald de Andrade nunca estiveram separados, e a única maneira correta de entender a sua vida, a sua obra e estas Memórias, é considerá-los deste modo. (Prefácio inútil. In ANDRADE, 1974).
\end{abstract}

$\mathrm{Na}$ segunda metade do livro nota-se-lhe uma forte alteração, principalmente porque a narrativa assume um tom marcado pela angústia. As razões mais visíveis desse desvio recaem sobretudo nas dificuldades de ordem financeira que a família de Oswald atravessa, além dos casos de amor um tanto estrepitosos como o que o autor mantém com a dançarina adolescente Landa, que conhecera ainda criança no navio que os levara à Europa. O modo de narrar as vicissitudes de seu romance e as desavenças que tal situação provoca em relação ao pai e Kamiá, mãe de seu primeiro filho, distinguem-se do movimento habitual da narrativa, que passa a basear-se em um estilo elíptico, de frases curtas e às vezes imprecisas. Para tanto, contribui a reprodução do Perfeito cožinheiro das almas deste mundo, diário da garçonnière alugada pelo autor à Rua Libero Badaró, no centro de São Paulo. Curioso que a fidelidade documental do diário só faz acentuar a complicação da narrativa, voltada agora para a enorme agitação interior que toma conta do autor. Em termos de composição narrativa, Antonio Candido uma vez mais mostra-nos como ocorre o processo no texto de apresentação ao livro de Oswald de Andrade, a que denominou de "Prefácio inútil":

\footnotetext{
$\mathrm{Na}$ primeira parte, quando a pesquisa do passado vai encontrar o próprio nascedouro das emoções, percebemos um trabalho atento da inteligência, organizando os dados da memória num sistema evocativo mais inteiriço. À medida, porém, que vai passando à idade adulta, e o material evocado corresponde a uma fase de personalidade já constituída, a elaboração sistemática cede lugar à notação. O impressionismo se desenvolve, por vezes, de modo a superar a própria verossimilhança, fragmentando a realidade na poalha dos dados da sensibilidade e desta maneira dando acesso a um mundo tornado equivalente ao imaginário da ficção. Aqui, nada separa Oswald de Andrade dos seus personagens. Ele se torna o seu maior personagem, operando a fusão poética do real e do fantástico. (Prefácio inútil. In ANDRADE, 1974).
} 


\title{
Drummond, Murilo Mendes e Pedro Nava
}

Nos anos de 1960 a literatura memorialística no Brasil já havia atingido certo grau de maturidade, o que tornava a ambientação propícia ao surgimento de formas mais ou menos insólitas dentro do gênero. Estas vieram nas obras autobiográficas de dois poetas de elevada estatura literária: Carlos Drummond de Andrade e Murilo Mendes. Insólitas, porque tais obras fugiam do modelado de prosa comum aos textos de memórias. Boitempo (1968) e Menino antigo (Boitempo II) (1973), de Drummond, são obras poéticas escritas em versos de métrica variada, formando poemas também de dimensão variada. A idade do serrote (1968), de Murilo Mendes, está composto em prosa, mas de tal modo aparentada à poesia que poderia ser concebido como tal. Antonio Candido atribui-lhe a denominação "prosa-poesia" (CANDIDO, 1987, p. 54).

Nestes autores a presença mais ostensiva da elaboração literária reafirma a possibilidade de um tratamento fortemente artístico a ser dispensado aos aspectos privados da vida pessoal. Naturalmente o resultado aparecerá na forma de livros com matizes poéticos e ficcionais.

Carlos Drummond de Andrade sempre apresentou, em meio a sua produção, uma temática voltada para a memória; é de se reparar o quanto este termo é importante na obra do poeta. Com Boitempo e Menino antigo o que sucede são memórias em forma de poema, diferença que promove uma mudança de tom, visto que as duas obras permitem "discernir um veio autobiográfico sem amargura, em contraste com a notória acidez denotada pelo emissor dos versos em relação a si mesmo no restante da obra" (CANDIDO, 1987, p. 55). Desaparecem por ora as inquietudes que marcam a produção anterior para figurar em seu lugar uma visão das coisas mais tranquila, um humor mais brejeiro, resultantes de um olhar que contempla, por assim dizer, um "eu antigo", descobridor do mundo e de seus descompassos e próximo do desejo de onipotência próprio das crianças:

Iniciação Literária

\author{
Leituras! Leituras! \\ Como quem diz: Navios... Sair pelo mundo \\ voando na capa vermelha de Júlio Verne. \\ Mas por que me deram para livro escolar \\ a Cultura dos Campos de Assis Brasil? \\ O mundo é só fosfatos - lotes de 25 hectares \\ - soja - fumo - alfafa - batata-doce - mandioca - \\ pastos de cria - pastos de engorda. \\ Se algum dia eu for rei, baixarei um decreto \\ condenando este Assis a ler a sua obra.
}

(ANDRADE, 1978, p. 121).

É assim que por meio de seus versos Drummond vai fixando, como todo bom memorialista, as imagens fugidias da cidade natal, o ritmo e os costumes da vida que ali se levava, os seus personagens marcantes, a iniciação amorosa, a escola, a vida religiosa, os parentes, os festejos, todo um mundo, enfim, recuperado com grande vigor evocativo.

A idade do serrote infunde também à matéria da memória um acento artístico por meio de recursos variados, dos quais vale a pena destacar alguns para se ter uma amostra do poder expressivo de Murilo Mendes também nesse gênero.

Antonio Candido já chamou a atenção para o ajuste que o autor efetua entre o discurso e o tema abordado, exemplificando com a variação apresentada pelos períodos quanto a suas dimensões. Por isso as lembranças iniciais da existência são expressas em sintagmas nominais coordenados entre si, "quando são referidos fatos e circunstâncias anteriores à possibilidade de a 
memória concatenar" (CANDIDO, 1987, p. 58). Tomemos apenas um dos muitos pequenos blocos que aparecem logo no início da obra: "As babás. A noite obscura do corpo. Histórias, parlendas, orações. Etelvina. Sebastiana" (MENDES, 1968, p. 6). São como que fiapos de memória despontando do fundo meio indistinto em que jaziam. Quando os fatos recordados se referem a uma época posterior, com a memória um pouco mais assentada, a tendência do discurso é tornar-se mais organizado. Outro recurso está no notável aproveitamento da sonoridade, que às vezes o próprio autor gosta de explicitar. O final do capítulo "Analu", sobre a namoradinha de dez anos, traz um discurso direto afetivo - "Bobo!" - cujos bês desencadeiam e prolongam o beijo que trocam: "Beijamo-nos. Sua boca sabe a balas de bergamota" (MENDES, 1968, p. 25). Em outro capítulo, a respeito de um circo na cidade, diz: "O nome do leão era Marruzko. Esses dois erres, com o zê azedo e o ká cortante, mais o urro do u no centro, formavam um composto que me aterrorizava" (MENDES, 1968, p. 29-30). Além desses recursos sonoros, encontramos também neologismos como, por exemplo, "cobranoratizei-me" (MENDES, 1968, p. 63), no capítulo sobre Cláudia, de excepcional beleza. A invenção chega à mescla de vocábulos de outras línguas, a uma pontuação às vezes muito particular, às construções curiosas, principalmente no capítulo "Momentos e frases".

O valor das memórias de Pedro Nava foi reconhecido de imediato. Antonio Candido colocou-se entre os primeiros a chamar a atenção para a importância de Baú de ossos, logo que a obra apareceu: "Baú de ossos, aliás, é singular, por constituir uma estréia literária aos 70 anos e situar o gênero autobiográfico nas alturas raras da verdadeira criação. Não tenho dúvida em dizer que este livro me parece o mais importante dentre os publicados em 1972"' (CANDIDO, 1972, p. 12). O crítico dedicaria reflexões essenciais sobre a autobiografia na forma de poesia e ficção em autores mineiros. É nele que Pedro Nava surge na companhia sugestiva de Carlos Drummond de Andrade e Murilo Mendes. Diz o crítico, ratificando o seu favorável ponto de vista acerca do autor:

\footnotetext{
Antes de abordar o estudo de sua obra conviria lembrar que, se estamos habituados a tratar Drummond e Murilo na categoria dos maiores escritores, a presença entre eles de Pedro Nava pode espantar alguns, porque a sua revelação é recente e as pessoas ainda não se habituaram a aceitar a sua eminência ou admitir que um livro de memórias possa ter a altura das grandes obras literárias. Ora, justamente porque estou convencido desde o primeiro momento de que assim é, ou seja, de que Pedro Nava é um dos grandes escritores brasileiros contemporâneos, não hesitei em situá-lo na devida companhia. Por esta mesma razão tratarei dele mais longamente que dos outros dois, há muito consagrados e gloriosos. (CANDIDO, 1987, p. 61).
}

Para um pequeno exemplo da acuidade de Antonio Candido na compreensão da obra de Pedro Nava, que não perdia oportunidade de incluir um estrangeirismo em seus escritos, lembrese o seu comentário abaixo reproduzido, no propósito de evidenciar o que isto representava de lucidez por parte do autor na sua relação com outra cultura:

Esse mineiro-cearense, profundamente enraizado na terra, esposando como ninguém e nas camadas mais fundas o gênio do idioma, emprega no entanto com a maior naturalidade e grande força expressiva palavras francesas aportuguesadas, tornando-as necessárias à anatomia e ao sentido da frase.

Não se trata do hábito meio snob e colonial, predominante no primeiro quarto deste século de intercalar a palavra ou a frase francesa, deixando-as intactas como pedras preciosas, ou como objeto não-digerido; trata-se de devorá-las e assimilá-las, o que equivale (nesses livros tão imbuídos de Proust) a um sinal de entendimento, de inteligência, em relação a uma das nossas culturas matrizes. (CANDIDO, 1987, p. 69).

Ainda no mesmo estudo, note-se uma rápida referência a um escritor da estima de Antonio Candido - Cyro dos Anjos -, que, embora não seja ali o centro de interesse, recebe uma 
bonita expressão para qualificar suas memórias: "bruma lírica" (CANDIDO, 1987, p. 54). De fato, A menina do sobrado transmite a sensação de que o mundo pretérito emana de uma interioridade, envolto em emoções singulares, íntimas, com características de conteúdo poético e simpatia imaginativa.

\section{Apolonio de Carvalho}

Exemplo de obra com ênfase na própria trajetória política é o de Apolonio de Carvalho, cujas memórias - Vale a pena sonhar - foram publicadas em 1997. No prefácio, Antonio Candido resume com a agudez costumeira as suas linhas de força. Aludindo às lutas em que o autor se engajou, enfatiza que tal participação representava a busca de uma sociedade mais justa e mais fraterna, distante de qualquer pretensão de caráter puramente pessoal. O trecho abaixo mostra o tom de suas considerações:

Este livro é feito com paixão discreta e sincera por um homem que pode olhar o passado certo de que deu conta da sua tarefa muito além do que requeria o dever. E é o livro de alguém dotado de rara capacidade de viver rigorosamente conforme as suas convicções socialistas, constituídas bem cedo num processo de amadurecimento descrito nessas páginas.

$[\ldots]$

O livro de Apolonio de Carvalho, que deve ser lido com este espírito, atrai além disso pela boa qualidade da escrita e pela franqueza despretensiosa com que tudo é narrado, denotando um espírito inquieto, capaz de perceber as contradições, sujeito às dúvidas que permitem o progresso ideológico e preparam soluções mais humanas. (CANDIDO in CARVALHO, 1997, p. 15-16).

A simpatia de Antonio Candido pela obra de Apolonio de Carvalho dá-se nos planos da escrita, dada sua condição de grande crítico, e também no das ideias, pois não é necessário relembrar o quanto ele devotou-se igualmente às causas mais nobres em nome do convívio humano baseado na dignidade.

\section{CONSIDERAÇÕES FINAIS}

Para finalizar, resta dizer a título de curiosidade que na obra de alguns memorialistas Antonio Candido surge propriamente como personagem citada. É o caso do livro de Luiz Martins, Um bom sujeito. Fruto de uma encomenda da Secretaria Municipal de Cultura de São Paulo, estendida também a outros autores com o propósito de colher depoimentos de figuras ligadas ao universo cultural da cidade, as memórias do autor relatam com frequência situações pitorescas e divertidas, como a do II Congresso Brasileiro de Escritores, realizado em Belo Horizonte no ano de 1947:

Eu me espantava com a assiduidade de Drummond e de Rodrigo. - "Vocês só são boêmios em Belo Horizonte", dizia-lhes; e, no auge do entusiasmo, propunha: - "Por que não nos mudamos todos para cá?" Mas os mais divertidos do grupo (vejam como são as coisas) eram os antigos chatos-boys da geração "coca-cola": Antonio Candido e Décio de Almeida Prado. O primeiro, então, promoveu verdadeiros shows, entoando canções francesas em dupla com o Décio, ou fazendo imitação de gente conhecida, com admirável perfeição e de maneira engraçadíssima. (MARTINS, 1983, p. 125).

Outro exemplo notório figura nas memórias de Afonso Arinos de Melo Franco, $A$ alma do tempo, em que se narram as vicissitudes que marcaram o famoso concurso na Universidade de São Paulo, em 1945, para a cátedra de Literatura Brasileira. Antonio Candido foi um dos candidatos, juntamente com Oswald de Andrade, tendo Afonso Arinos participado como 
membro da banca examinadora.

Como se viu, a intenção principal destas páginas foi percorrer segmentos da obra de Antonio Candido relativas à literatura de memórias no Brasil. As observações e ilações interpostas procuraram adequar-se às suas posições e ao espírito que as orientaram. Naturalmente não houve pretensão de oferecer um quadro completo, mas tão somente de sugerir a postura ativa e sempre atenta do estudioso, o que nos leva a imaginar que o memorialismo brasileiro atingiu sua maioridade, mostrando-se já consolidado no nosso panorama literário.

\section{REFERÊNCIAS BIBLIOGRÁFICAS}

ANDRADE, Carlos Drummond de. Boitempo. 3. ed. Rio de Janeiro: José Olympio, 1976. Menino antigo (Boitempo II). 3. ed. Rio de Janeiro: José Olympio, 1978.

ANDRADE, Oswald de. Um homem sem profissão. 2. ed. Rio de Janeiro: Civilização Brasileira, 1974. (Vera Cruz)

ANJOS, Cyro dos. A menina do sobrado. Rio de Janeiro: José Olympio; Brasília: INL, 1979.

BARRETO, Afonso Henriques de Lima. Diário intimo. São Paulo: Mérito, 1953.

Diário do hospício; O cemitério dos vivos. Rio de Janeiro: Secretaria Municipal de Cultura, Depto. Geral de Documentação e Informação Cultural, Divisão de editoração, 1993. (Biblioteca Carioca)

BOSI, Alfredo. História concisa da literatura brasileira. 2. ed. São Paulo: Cultrix, 1978.

. O Pré-Modernismo. 5. ed. São Paulo: Cultrix, s.d. (A literatura brasileira, vol. 5)

CAMPOS, Humberto de. Memórias. São Paulo: Mérito, 1962.

. Memórias inacabadas. São Paulo: Mérito, 1962.

Reminiscências. São Paulo: Mérito, 1962.

CANDIDO, Antonio. Formação da literatura brasileira. 5. ed. Belo Horizonte: Itatiaia; São Paulo: Edusp, 1975. 2 vols.

A educação pela noite e outros ensaios. São Paulo: Ática, 1987.

Ficção e confissão. Rio de Janeiro: Editora 34, 1992.

A Literatura Brasileira em 1972. Revista Iberoamericana, Pittsburgh, Universidade de Pittsburgh, vol. XLIII, n. 98-99, jan.-jun. 1977.

CARVALHO, Apolonio de. Vale a pena sonhar. Rio de Janeiro: Rocco, 1997.

FRANCO, Afonso Arinos de Melo. A alma do tempo. (Reunião de toda a obra de memórias). Rio de Janeiro: José Olympio- INL, 1979. 
FREYRE, Gilberto. O velho Félix e suas "Memórias de um Cavalcanti". Recife: FUNDAJ/Editora Massangana, 1989. [Esta edição é um fac-símile da publicada no Rio de Janeiro, pela José Olympio, em 1959].

MARTINS, Luiz. Um bom sujeito. Rio de Janeiro: Paz e Terra; São Paulo: Secretaria Municipal de Cultura, 1983. (Depoimento)

MENDES, Murilo. A idade do serrote. Rio de Janeiro: Sabiá, 1968.

MEYER, Augusto. Textos críticos; seleção e introdução de João Alexandre Barbosa. São Paulo: Perspectiva; Brasília, INL, Fundação Nacional Pró-Memória, 1986. (Textos)

NAVA, Pedro. Baú de ossos. 4. ed. Rio de Janeiro: José Olympio, 1974.

_. Chão de ferro. Rio de Janeiro: José Olympio, 1976.

RAMOS, Graciliano. Infância. 7. ed. São Paulo: Martins, 1969. Memórias do cárcere. 24. ed. Rio de Janeiro, São Paulo: Record, 1989. 2 vols.

SODRÉ, Nelson Werneck. O que se deve ler para conbecer o Brasil. 5. ed. Rio de Janeiro: Civilização Brasileira, 1976. (Retratos do Brasil)

TAUNAY, Alfredo D’Escragnolle. Memórias. São Paulo: Melhoramentos, s.d. 